\title{
Students Satisfactory Indexs of Pascasarjana Services of Universitas Ahmad Dahlan
}

\author{
Abdul Choliq Hidayat* \\ Universitas Ahmad Dahlan \\ Agus Siswanto* \\ Universitas Ahmad Dahlan
}

hacholiqh@gmail.com

\begin{abstract}
The research aim was to calculate Students Satisfactory Indexs of Pascasarjana Study Programs Services Of Universitas Ahmad Dahlan who has 12 (twelve) programs,. It has at least 850 students in 2018. Pascasarjana needs some feedback in order to increase their quality of students service satisfactory as high as possible to reach optimum level, and fulfill qualification of succeed its business. This research wanted to measure the up dated customer service satisfactory and gave feedback to Universitas Ahmad Dahlan for their continuous improvement program. The research method used quantitative approach to primary data of customer questioneer and scondary data of Pascasarjana Universitas Ahmad Dahlan. The questioneers had distributed to student that has one year full study, by proporsional random sampling to 11 of 12 study programs, 10 examplar each study program, totally about 110 examplars, returned back about 110 examplars (100\%), and than the data have been calculated by SPSS method version 10.0. The result of research was students satisfactory indexs of the services of Pascasarjana Study Programs reached good and significance level at all study programs, as the index, at point 4.307 root mean at 1 until 5 at Likert scale. They favored empathy dimension at point 4.389, and than assurance (4.347), tangible (4.331), responsiveness (4.295), and reliability (4.185). To be adviced that all of study programs must increase giving their services until reach the highest level of all dimensions, that are: tangibles, responsiveness, reliability, emphaty, dan assurance. Both of hyphotesis have proven that all of five variables, together or partially were significantly and positively influenced toward Students Satisfactory of Pascasarjana Study Programs Services Of Universitas Ahmad Dahlan
\end{abstract}

Key word: satisfactory, service, pascasarjana

\section{Pendahuluan}

Salah satu tugas utama Perguruan Tinggi adalah memproses kaderisasi dalam rangka menyiapkan pemimpin masa depan, oleh karena itu Tridharma Perguruan Tinggi bukan hanya sebagai kewajiban yang harus dilaksanakan, tetapi implementasinya harus dapat diwujudkan manfaatnya bagi para stakeholders terutama mahasiswa dan masyarakat, dan mempunyai peran sangat penting dalam kehidupan berbangsa dan bernegara, diatur melalui Undang-Undang Nomor 20 Tahun 2003 tentang Sistem Pendidikan Nasional Pasal 20 Ayat 2, yang menetapkan bahwasanya perguruan tinggi berkewajiban menyelenggarakan pendidikan, penelitian, dan pengabdian kepada masyarakat.

Perguruan tinggi (PT) sebagai sektor strategis yang bertujuan untuk menghasilkan sumber daya manusia yang bermutu dihadapkan pada globalisasi pendidikan, yang ditandai adanya persaingan yang tajam antar perguruan tinggi. PT yang kurang bermutu dipastikan akan terancam bubar. Persaingan yang cukup ketat antar perguruan tinggi, sebagai lembaga pendidikan dituntut memperhatikan mutu pendidikan agar unggul dan terpilih 
dalam persaingan tersebut. Persaingan antar perguruan tinggi dan antar program studi juga merupakan salah satu faktor pilihan yang rumit, kualitas perguruan tinggi menjadi penentu. Badan Akreditasi Nasional Perguruan Tinggi (BAN-PT) adalah jawaban atas tuntutan masyarakat agar perguruan tinggi dapat memenuhi jaminan kualitas (quality assurance), pengendalian kualitas (quality control), dan perbaikan kualitas (quality improvement). Program Akreditasi perguruan tinggi merupakan jawaban untuk meningkatkan kualifikasi lebih bermutu bagi universitas negeri dan swasta di Indonesia.

Universitas Ahmad Dahlan telah mendirikan beberapa program studi dan selalu berupaya melakukan peningkatannya untuk memenuhi standar baku mutu yang ditetapkan oleh BAN-PT selaku institusi yang didirikan oleh Pemerintah melalui program peningkatan mutu berkelanjutan dan melaksanakan akreditasi berkala, baik internal maupun eksternal. Salah satu poin penting dan merupakan kualifikasi yang tinggi diantaranya adalah kepuasan mahasiswa yang tinggi terhadap pelayanan program pendidikan yang dilaksanakan dan keharusan secara periodik diteliti, agar program perbaikan berkelanjutan oleh program studi dapat dijalankan dengan baik.

Sukanti (2009:23-24) menyatakan bahwa pengetahuan tentang kepuasan mahasiswa, sebagai pelanggan atas layanan pendidikan, akan memberikan banyak manfaat, diantaranya: kepuasan mahasiswa berfungsi sebagai pedoman untuk mengarahkan seluruh organisasi ke arah pemenuhan kebutuhan mahasiswa sehingga menjadi sumber dari keunggulan daya saing yang berkelanjutan. Menurut Philip Kotler (2005) ketidakpuasan itu muncul karena adanya kesenjangan antara: (1) harapan konsumen dan persepsi manajemen., (2) persepsi manajemen dan spesifikasi kualitas jasa., (3) spesifikasi kualitas jasa dan penyampaian jasa, (4) penyampaian jasa dan komunikasi eksternal, dan (5) jasa yang dialami oleh pelanggan dibandingkan dengan jasa yang diharapkan.

Menurut Tjiptono (2012:11) ada lima faktor yang relevan untuk menjelaskan kualitas pelayanan yang di kenal dengan model SERVQUAL yaitu reliability, responsiveness, assurance, empathy, dan tangibles. Kelima faktor kualitas pelayanan tersebut merupakan kunci utama untuk meningkatkan kepuasan pelanggan yang pada akhirnya berujung pada loyalitas pelanggan. Pelayanan yang berkualitas dan mampu memuaskan pelanggan merupakan kunci loyalitas pelanggan karena terbanyak konsumen yang tidak puas memilih untuk tidak melakukan pengaduan dan sebagian besar cukup menghentikan pembeliannya (Kotler, 1997).

Permasalahan dalam penelitian ini dapat dirumuskan sebagai berikut;

a. Apakah faktor-faktor pelayanan yang terdiri reliability, responsiveness, assurance, emphaty dan tangible secara parsial mempengaruhi kepuasan mahasiswa Pascasarjana UAD?

b. Apakah faktor-faktor reliability, responsiveness, assurance, emphaty dan tangible secara bersama-sama mempengaruhi kepuasan mahasiswa Pascasarjana UAD?

Tujuan dari penelitian ini adalah sebagai berikut:

a. Menguji apakah faktor-faktor pelayanan yang terdiri dari reliability, responsiveness, assurance, emphaty dan tangible secara parsial mempengaruhi kepuasan mahasiswa Pascasarjana UAD.

b. Menguji apakah faktor-faktor reliability, responsiveness, assurance, emphaty dan tangible secara bersama-sama mempengaruhi kepuasan mahasiswa Pascasarjana UAD. 


\section{Landasan Teori daan Pengembangan Hipotesis}

Empat karakteristik pokok jasa yang membedakannya dengan barang (Tjiptono, 1997). Keempat karakteristik tersebut meliputi:

\section{a. Intangibility}

Jasa bersifat intangible, artinya tidak dapat dilihat, dirasa, diraba, dicium atau didengar sebelum dibeli.

b. Perishability

Jasa yang merupakan komoditas tidak tahan lama dan tidak dapat disimpan. Menurut Stanton et al. (1991), ada pengecualian dalam karakteristik perishability dan penyimpanan jasa. Dalam kasus tertentu jasa dapat disimpan yaitu dalam bentuk pemesanan, peningkatan permintaan akan suatu jasa pada saat permintaan sepi dan penundaan penyampaian jasa.

c. Inseparability

Jasa dijual terlebih dahulu baru kemudian diproduksi dan dikonsumsi. Interaksi antara penyedia jasa dan pelanggan bersifat khusus.

d. Variability

Jasa bersifat sangat variabel karena merupakan non standardized output, yang artinya banyak variasi bentuk, kualitas dan jenis tergantung pada siapa, kapan dan dimana jasa tersebut dihasilkan dan dipesan.

Terdapat dua faktor utama yang mempengaruhi kualitas jasa menurut Parasuraman et al. (1985), yaitu;

1. Apabila jasa yang diterima atau dirasakan (perceived service) sesuai dengan yang diharapkan, maka kualitas jasa dipersepsikan baik dan memuaskan.

2. Apabila jasa yang diterima melampaui harapan pelanggan, maka kualitas jasa dipersepsikan sebagai kualitas yang ideal.

Model-model yang dapat digunakan untuk menganalisis kualitas jasa, tergantung pada tujuan analisis, jenis perusahaan, dan situasi pasar. Setidaknya terdapat tiga kelompok utama (Kotler, 1997), yaitu customer-perceived quality, the processes in the creation of the service, dan the whole service (system models).

Lima dimensi pokok kualitas jasa (Zeithaml et al., 1996:118), yaitu:

1. Bukti langsung (tangibles); meliputi fasilitas fisik, perlengkapan pegawai, dan sarana komunikasi.

2. Keandalan (reliability); yakni kemampuan memberikan pelayanan yang dijanjikan dengan segera, akurat, dan memuaskan.

3. Daya tanggap (responsiveness); yaitu keinginan para staf untuk membantu para pelanggan dan memberikan pelayanan dengan tanggap.

4. Jaminan (assurance); mencakup pengetahuan, kemampuan, kesopanan dan sifat dapat dipercaya yang dimiliki para staf, bebas dari bahaya risiko dan keragu-raguan.

5. Empati (emphaty); meliputi kemudahan dalam melakukan hubungan, komunikasi yang baik, perhatian pribadi, dan memahami kebutuhan para pelanggan.

Menurut Kotler (2005) ketidakpuasan itu muncul karena adanya kesenjangan antara: (1) harapan konsumen dan persepsi manajemen, (2) persepsi manajemen dan spesifikasi kualitas jasa, (3) spesifikasi kualitas jasa dan penyampaian jasa, (4) penyampaian jasa dan komunikasi eksternal, dan (5) jasa yang dialami oleh pelanggan dan jasa yang diharapkan. 
Abdul Choliq Hidayat, Agus Siswanto

\section{Hipotesis Penelitian}

Berdasarkan latar-belakang masalah, rumusan masalah, tujuan penelitian dan landasan teori, maka hipotesis yang diajukan dalam penelitian ini adalah:

H1: Faktor-faktor pelayanan yang terdiri dari tangible, reliability, responsiveness, assurance, dan emphaty secara parsial mempengaruhi kepuasan mahasiswa Pascasarjana UAD.

$\mathrm{H} 2$ : Faktor-faktor tangible, reliability, responsiveness, assurance, dan emphaty secara bersama-sama mempengaruhi kepuasan mahasiswa Pascasarjana UAD.

\section{Metode Penelitian}

Analisis deskriptif digunakan untuk mengetahui indeks kepuasan atas kualitas proses belajar mengajar yang diterima oleh mahasiswa. Pengukuran indeks kepuasan mahasiswa menilai kualitas proses belajar mengajar dilakukan melalui langkah-langkah sebagai berikut: (1) Menentukan dimensi-dimensi kualitas layanan Dimensi Tangibles, Dimensi ini menilai fasilitas: kenyamanan ruang kuliah, kenyamanan ruang diskusi, kemudahan akses internet, kelengkapan literatur perpustakaan, kebersihan toilet, kemudahan parkir kendaraan, dan keramahan tenaga pendidikan (tendik). Teori yang diberikan berbobot, bermanfaat untuk bekerja, konsentrasi yang diinginkan tersedia, teori dapat teraplikasikan dan seimbang. (2) Dimensi Reliability. Dimensi ini berkenaan dengan Pelayanan Akademik yang cermat dan Pelayanan urusan administrasi yang cepat. (3) Dimensi Responsiveness, berkenaan dengan: Kesiapan dosen dalam membimbing tesis, kemudahan berkomunikasi, cepat tanggap melayani keperluan mahasiswa, dan mengatur ruang kelas untuk kuliah. (4) Dimensi Assurance, berkenaan dengan kedisiplinan dalam jadwal perkuliahan, memiliki kemampuan yang baik memberikan kuliah, bekerja dengan terampil, sikap yang baik dalam memberikan pelayanan akademik. (5) Dimensi Empathy, berkenaan dengan: pemberian perhatian kepada setiap mahasiswa dan cepat tanggap menyelesaikan keluhan mahasiswa.

Variabel yang digunakan dalam penelitian ini adalah sebagai berikut:

1. Kepuasan mahasiswa sebagai pelanggan faktor Tangible meliputi;

a. Kepuasan mahasiswa ketika berhubungan dengan bagian administrasi.

b. Kepuasan mahasiswa ketika berhubungan dengan bagian keuangan.

c. Kepuasan mahasiswa ketika berhubungan dengan bagian administrasi dan pengajaraan.

d. Kepuasan mahasiswa ketika berhubungan dengan bagian keamanan dan petugas parkir.

e. Kepuasan pelanggan yang berhubungan dengan fasilitas pascasarjana yang ada di UAD;

- penampilan karyawan dan dosen.

- keramahan dan kepatutan perlakuan karyawan dan dosen.

- tersedianya panduan dan penjelasan program.

- kenyamanan ruangan kelas dan fasilitas lainnya.

- jalur-jalur antrian pada berbagai fasilitas.

- perhatian dan bantuan yang diberikan karyawan dan dosen.

- proses penyelesaian segala urusan keperluan mahasiswa.

- kemudahan menghubungi lewat telepon untuk akad janji pertemuan dan lainnya.

- sarana parker mobil maupun motor serta sepeda.

- fasilitas penunjang misalnya ATM (Anjungan Tunai Mandiri)

2. Kepuasan mahasiswa faktor Reliability meliputi :

a. Kecepatan pelayanan. 
b. Keakuratan atau ketepatan perhitungan jumlah keuangan ataupun lainnya, nilai setiap mata kuliah dan atau tugas.

c. Kesesuaian rencana program yang dijanjikan dan realisasi program sesuai yang dijanjikan.

3. Kepuasan mahasiswa faktor Responsiveness meliputi :

a.Kesiapan karyawan dan dosen dalam memberikan bantuan dan pelayanan kepada mahasiswa sesuai yang dijanjikan.

b.Penjelasan serta pembinaan atas penggunaan dana dan pembiayaan program.

c. Penjelasan program yang telah dijanjikan dan disepakati.

4. Kepuasan mahasiswaa faktor Assurance meliputi :

a. Pengetahuan dan kemampuan yang dimiliki karyawan dan dosen.

b. Sopan santun karyawan dan dosen.

c. Sifat dapat dipercaya yang dimiliki karyawan dan dosen.

d. Ketepatan perjanjian pertemuan.

5. Kepuasan mahasiswa faktor Emphaty meliputi :

a. Sifat mudah bergaul dan berkomukasi dari karyawan dan dosen.

b. Perhatian pribadi yang diberikan karyawan dan dosen.

c. Pemberian alternatif solusi jika mahasiswa mendapatkan kesulitan.

d. Penjelasan ulang dan tindak lanjut program jika diperlukan.

\section{Model Penelitian}

Sampel penelitian ini adalah mahasiswa pasca sarjana yang aktif minimal 1 (satu) tahun terakhir, yakni tahun 2018. Metode pengambilan sampel yang digunakan adalah proporsinal random sampling, yaitu suatu cara pengambilan sampel, dimana sampel yang dipilih didasarkan pada proporsi yang diusahakan secara adil, secara random sampling atau acak, sehingga setiap anggota populasi mempunyai kesempatan yang sama untuk dipilih menjadi sampel. Teknik sampling yang digunakan adalah cluster sampling (sampling program studi, bukan konsentrasi). Teknik ini digunakan untuk menentukan sampel jika objek yang akan diteliti atau sumber data sangat luas (Azwar, 1998).

Sampel masing-masing prodi ditentukan adalah 10 mahasiswa dari seluruh populasi pada 11 (sebelas) prodi. Setiap prodi diberikan sampling masing-masing sebanyak 10 sehingga jumlah sampel seluruhnya adalah 110 (seratus sepuluh) mahasiswa. Prodi dimaksud adalah : Pend. Fisika, Pend. Bhs Inggris, Psikologi, Farmasi, Psikologi Profesi, Manajemen Pendidikan, Teknik Informatika, Pendidikan Matematika, Pendidikan Vokasi, Manajemen, dan Pendidikan Agama Islam. Populasinya adalah seluruh mahasiswa pascasarjana berjumlah total sebanyak 850 mahasiswa pada akhir tahun 2018. Pengujian validitas dan reliabilitas dilakukan dengan menggunakan program komputer SPSS versi 10.0. Pengujian asumsi dilakukan dengan menggunakan uji autokorelasi, uji multikolinieritas, uji heterokedastisitas, dan uji normalitas.

Hipotesis yang telah dirumuskan diuji dengan menggunakan beberapa teknik pengujian, yaitu linier multiple regression, uji t statistik, dan uji F statistik.

Pascasarjana UAD melaksanakan kegiatan-kegiatan dalam pelaksanaan program sebagai berikut :

1. Menyelenggarakan pendidikan yang mampu menghasilkan lulusan yang profesional dan inovatif serta dijiwai ajaran Al-Islam. 
2. Menyelenggarakan penelitian kreatif, inovatif berbasis ilmu pengetahuan dan teknologi.

3. Menyelenggarakan pengabdian pada masyarakat dan kerjasama yang bermanfaat bagi masyarakat, bangsa dan negara.

4. Menyelenggarakan dan mengamalkan ilmu pengetahuan dan teknologi untuk kemaslahatan ummat sebagai manifestasi prinsip Islam sebagai rahmatan lil-alamin.

\section{Hasil Penelitian dan Pembahasan}

Kuesioner yang telah didistribusikan sebanyak 110 eksemplar dan kembali setelah diisi oleh para mahasiswa Pascasarjana yang memenuhi syarat sebanyak 110 eksemplar atau $100 \%$ dalam waktu 3 (tiga) bulan.

Data responden laki-laki sebanyak 36 orang $(32,7 \%)$ dan perempuan sebanyak 74 orang $(67,3 \%)$, sedang kuliah pada semester 3 sebanyak 78 orang $(70,91 \%)$, semester 4 sebanyak 21 orang $(19,09 \%)$, dan semester 5 sebanyak 11 orang $(10 \%)$.

Dengan menggunakan uji Confirmatory Factor Analysis (CFA) hasil uji validitas masing-masing variable sebagai berikut :

Tabel 1. Hasil Confirmatory Factor Anaysis (CFA)

\begin{tabular}{|c|c|c|c|}
\hline Variabel & Jumlah Indikator & $\begin{array}{c}\text { Komponen Rata- } \\
\text { Rata }\end{array}$ & Hasil \\
\hline Tangibles & 13 & 0,678 & Valid \\
\hline Reliability & 9 & 0,747 & Valid \\
\hline Responsiveness & 6 & 0,779 & Valid \\
\hline Assurance & 9 & 0,841 & Valid \\
\hline Empathy & 7 & 0,862 & Valid \\
\hline
\end{tabular}

Sumber: Hasil Olah Data, 2019

Hasil uji CFA semua indikator yang digunakan dalam penelitian ini valid dan dapat digunakan lebih lanjut.

Hasil uji Reliabilitas dilakukan dengan menguji nilai Cronbach's Alpha $>0,5$ dan hasilnya sebagai berikut :

Tabel 2. Hasil Uji Reliabilitas

\begin{tabular}{|c|c|c|c|}
\hline Nomor & Variable & N of Item & $\begin{array}{c}\text { Cronbarch's } \\
\text { Alpha }\end{array}$ \\
\hline 1 & Tangibles & 13 & 0,607 \\
\hline 2 & Reliability & 9 & 0,922 \\
\hline 3 & Responsiveness & 6 & 0,675 \\
\hline 4 & Assurance & 9 & 0,837 \\
\hline 5 & Empathy & 7 & 0,845 \\
\hline
\end{tabular}

(Sumber : Hasil Olah Data, 2019)

Semua butir atau item penyataan dinyatakan reliabel karena memiliki nilai Cronbarch's Alpha $>0,6$, yang berarti intrumen atau kuisioner yang digunakan pada penelitian ini mempunyai hasil yang konsisten sehingga terpenuhi syarat penelitian dan dapat dilanjutkan.

\section{Data Statistik Diskriptif}



berikut :

Rekap hasil perhitungan statistik diskriptif penelitian ini dapat digambarkan sebagai

Tabel 3. Data Diskriptif Statistik

\begin{tabular}{|c|c|c|c|}
\hline & Mean & $\begin{array}{c}\text { Std. } \\
\text { Deviation }\end{array}$ & $\mathrm{N}$ \\
\hline Tangibles & 4,331 & .49866 & 110 \\
\hline Reliability & 4,347 & .56342 & 110 \\
\hline Responsiveness & 4,185 & .46754 & 110 \\
\hline Assurance & 4,295 & .43349 & 110 \\
\hline Empathy & 4,389 & .49337 & 110 \\
\hline
\end{tabular}

Sumber : Hasil Olah Data, 2019

Jumlah responden penelitian ini adalah 110 orang $(\mathrm{N}=110)$. Artinya jumlah data yang masuk sebanyak 110. Dengan mean atau rata-rata jawaban kuisioner semua di atas 4 . Artinya semua responden menyatakan setuju, bermakna pelayanan Pascasarjana kategori baik dan merasa puas terhadap semua variabel, yakni Tangibles, Reliability, Responsiveness, Assurance, dan Empathy dengan skor di atas 4. Hal ini bermakna bahwa seluruh variable secara bersama-sama berpengaruh signifikan terhadap kepuasan mahasiswa Pascasarjana. Hipotesis terbukti dan dapat diterima.

\section{Uji t}

Sedangkan untuk membuktikan hipotesa pada penelitian ini digunakan signifikansi uji $\mathrm{t}<0,05$ dengan hasil sebagai berikut :

\section{Tabel 4. Hasil Sig Uji-t}

Coefficients $^{\mathrm{a}}$

\begin{tabular}{|ll|c|c|c|c|c|}
\hline \multirow{2}{*}{ Model } & \multicolumn{2}{|c|}{$\begin{array}{c}\text { Unstandardized } \\
\text { Coefficients }\end{array}$} & $\begin{array}{c}\text { Standardized } \\
\text { Coefficients }\end{array}$ & \\
\cline { 3 - 5 } & & $\mathrm{B}$ & Std. Error & Beta & $\mathrm{t}$ & Sig. \\
\hline \multirow{4}{*}{1} & (Constant) & 2.043 & .342 & & 5.998 & .000 \\
& Tang & .465 & .241 & .362 & 5.331 & .000 \\
& Reli & .543 & .325 & .412 & 4.552 & .000 \\
& Resp & .471 & .455 & .466 & 4.998 & .000 \\
& Assu & .367 & .416 & .474 & 5.481 & .000 \\
& Empa & .463 & .374 & 438 & 5.478 & .000 \\
\hline
\end{tabular}

a. Dependent Variable : Puas

Nilai Signifikansi uji t kelima variabel yang berpengaruh positif signifikan terhadap kepuasan. Nilai Signifikansi uji t untuk lima variabel variabel $<0,05$ yaitu 0,000 . Artinya bahwa mahasiswa Pascasarjana yang bersedia menjadi sampel penelitian menyatakan puas dikarenakan kelima dimensi sikap bernilai tinggi, yaitu pelayanan Pascasarjana kepada mahasiswa Pascasarjana sangat diapresiasi.

Indeks Kepuasan Rata-rata Mahasiswa Program Studi Pascasarjana disajikan dalam tabel berikut ini. 
Tabel.5. Indeks Total Rata-rata Kepuasan Mahasiswa Pascasarjana

\begin{tabular}{|c|c|c|c|c|c|c|}
\hline No. & Prodi & Tangible & Assurance & Reliable & Responsiveness & Empathy \\
\hline 1. & Pend. Fisika & 4,321 & 4,734 & 4,244 & 3,945 & 4,056 \\
\hline 2. & Pend. Bhs. Inggris & 4,245 & 4,156 & 3,932 & 4,435 & 4,567 \\
\hline 3. & Psikologi & 4,146 & 4,267 & 4,145 & 4,092 & 4,553 \\
\hline 4. & Farmasi & 4,543 & 4,373 & 4,247 & 4,467 & 4,363 \\
\hline 5. & Psikologi Profesi & 4,443 & 4,538 & 4,073 & 4,253 & 4,333 \\
\hline 6. & $\begin{array}{l}\text { Manajemen } \\
\text { Pendidikan }\end{array}$ & 4,249 & 3,979 & 3,885 & 4,147 & 4,464 \\
\hline 7. & Teknik Informatika & 4,346 & 4,443 & 4,426 & 4,619 & 4,162 \\
\hline 8. & $\begin{array}{l}\text { Pendidikan } \\
\text { Matematika }\end{array}$ & 4,642 & 4,732 & 4,241 & 4,527 & 4,652 \\
\hline 9. & $\begin{array}{c}\text { Pendidikan Guru } \\
\text { Vokasi }\end{array}$ & 4,335 & 3,957 & 4,147 & 4,342 & 4,233 \\
\hline 10. & Manajemen & 4,046 & 4,274 & 4,136 & 4,232 & 4,444 \\
\hline 11. & $\begin{array}{l}\text { Pendidikan Agama } \\
\text { Islam }\end{array}$ & 4,327 & 4,358 & 4,556 & 4,183 & 4,341 \\
\hline & Rata-rata & 4,331 & 4,347 & 4,185 & 4,295 & 4,389 \\
\hline & Jumlah Total & \multicolumn{5}{|c|}{21,536} \\
\hline & ata-rata Total & & & & 4,307 . & \\
\hline
\end{tabular}

Sumber : Data diolah (2019).

Secara keseluruhan dapat disimpulkan bahwa jika dosen dan staf tenaga pendidikan semakin meningkatkan kelima dimensi pelayanan maka mahasiswa akan semakin puas. Hal ini membuktikan bahwa secara parsial Tangibles, Reliability, Responsiveness, Assurance, dan Empathy berpengaruh terhadap kepuasan mahasiswa Pascasarjana. Hal ini bermakna bahwa baik secara parsial maupun secara bersama-sama mempengaruhi kepuasan para mahasiswa Pascasarjana secara signifikan dan positif.

Indeks kepuasan total dibentuk dari lima dimensi kualitas pelayanan yaitu Tangibles, Assurance, Reliability, Responsiveness, dan Emphaty. Kelima dimensi tersebut menggambarkan kepuasan dari customer dalam hal ini mahasiswa Pascasarjana . Indeks kepuasan mahasiswa secara keseluruhan adalah sebesar 4,307 dan angka ini berada pada zona kepuasan tinggi tetapi belum mencapai sangat tinggi.

Sementara, indeks kepuasan mahasiswa terendah adalah 4,185 pada dimensi Reliability dan tertinggi adalah 4,389 pada dimensi Empathy. Dari indeks kepuasan total tersebut perlu dikaji kontribusi masing-masing dimensi. Indeks kepuasan total dibentuk dari kelima dimensi kualitas layanan. Analisis lebih rinci tentang indeks kepuasan mahasiswa menurut dimensi dapat disebutkan bahwa indeks kepuasan berbagai dimensi di program studi Pascasarjana, terlihat bahwa hampir semua dimensi telah mempunyai indeks kepuasan diatas 4,0. Ini berarti, kelima dimensi, yaitu responsiveness, reability, emphaty, assurance dan tangibles berada pada zona kepuasan tinggi. Terdapat dua dimensi, yakni Reliability dan Responsiveness, merupakan indeks kepuasan paling rendah jika dibandingkan dengan dimensi lainnya. Hal ini bermakna bahwa seluruh variable secara bersama-sama berpengaruh signifikan terhadap kepuasan mahasiswa Pascasarjana. Hipotesis terbukti dan dapat diterima. 


\section{Kesimpulan}

Berdasarkan pembahasan, maka hasil penelitian ini dapat disimpulkan bahwa:

1. Indeks kepuasan mahasiswa Pascasarjana UAD total dibentuk dari lima dimensi kualitas pelayanan yaitu Tangibles, Assurance, Reliability, Responsiveness, dan Emphaty. Kelima dimensi tersebut menggambarkan kepuasan dari mahasiswa Pascasarjana. Rata-rata Indeks kepuasan mahasiswa secara keseluruhan adalah sebesar 4,307 dan angka ini berada pada zona kepuasan tinggi tetapi belum mencapai sangat tinggi.

2. Indeks kepuasan mahasiswa rata-rata terendah adalah 4,185 pada dimensi Reliability dan tertinggi adalah 4,389 pada dimensi Empathy. Semakin besar empathy yang diberikan oleh dosen dan staf tenaga pendidikan maka mahasiswa akan semakin puas.

3. Kelima dimensi untuk mengukur kepuasan mahasiswa yaitu Tangibles, Assurance, Reliability, Responsiveness, dan Emphaty secara bersama-sama maupun secara parsial masing-masing berpengaruh signifikan dan positif.

Dari hasil penelitian ini, dapat diberikan saran untuk meningkatkan kepuasan mahasiswa Pascasarjana UAD.

1. Perlu mendapatkan perhatian Prodi Pascasarjana UAD pada dimensi Reliability dan Responsiveness yang memiliki indeks kepuasan rata-rata terendah. Dari indeks kepuasan total tersebut juga perlu dikaji kontribusi masing-masing dimensi. Ada beberapa hal yang harus diperhatikan bidang Reliability adalah antara lain : Agar materi kuliah diberikan oleh dosen secara jelas, Waktu yang disediakan oleh dosen untuk diskusi dan tanya jawab hendaknya memadai, Bahan ajar suplemen (handout, modul, soft copy file, dll) agar diberikan kepada mahasiswa untuk melengkapi materi perkuliahan, para Dosen agar mengembalikan hasil ujian dan tugas kepada mahasiswa dengan penilaian yang obyektif, Dosen agar datang tepat waktu, memulai dan mengakhiri kuliah sesuai waktunya, Dosen agar benar-benar menguasai materi bahasan sesuai dengan bidang keahliannya, Satuan Rencana Perkuliahan Studi yang dibuat dosen agar sesuai dengan yang diajarkan, Kemampuan staf hendaknya makin memadai untuk melayani administrasi kemahasiswaan, Kualitas layanan staf untuk memenuhi kepentingan mahasiswa hendaknya lebih memadai. Sedangkan bidang responsiveness antara lain: perlunya meningkatkan perhatian dosen pembimbing tesis, agar membantu mahasiswa menghadapi masalah akademik, menyediakan waktu untuk berkonsultasi, hendaknya ada bantuan pengobatan jika mahasiswa sakit di kelas, atau berobat kecelakaan dalam rangka studi, dan diharapkan ketersediaan beasiswa bagi mahasiswa berprestasi.

2. Para peneliti selanjutnya dapat meneliti faktor-faktor lain yang mempengaruhi kepuasan mahasiswa Pascasarjana UAD untuk memberikan masukan berharga bagi kesempurnaan pelayanan baik akademik maupun non akademik kepada mahasiswa.

\section{Daftar Pustaka}

Andespa, Roni. (2016). Strategi Pelayanan Bank Konvensional dan Syariah: Prioritas Pelayanan Fisik dan Empati. Al-Masraf: Jurnal Lembaga Keuangan dan Perbankan, 1 (2): 143-159.

Arikunto, Suharsimi, 2009. Manajemen Penelitian. Cetakan kesepuluh. Jakarta: PT Rineka Cipta. 
Azwar, Saifuddin. 1998. Metode Penelitian. Edisi ke 1. Putaka Pelajar. Yogyakarta.

Ghozali, Imam, 2002. Aplikasi Analisis Multivariate dengan Program SPSS. Semarang: Badan Penerbit Universitas Diponegoro.

2004. Model Persamaan Struktural, Konsep dan Aplikasi dengan Program Amos Vesi 5.0. Semarang: Universitas Diponegoro.

Giantari, dkk, 2008, "Analisis Kepuasan Mahasiswa Terhadap Proses Belajar Mengajar di Program Diploma III FE Universitas Udayana”, Buletin Studi Ekonomi, Vol. 13, No. 1, p. 52-66.

Kementrian Pendidikan Nasional Direktorat Jenderal Pendidikan Tinggi, 2010. Sistem Penjaminan Mutu Perguruan Tinggi (SPM-PT), Jakarta.

Kotler, Phillip. 1997. Manajemen Pemasaran: Analisis, Perencanaan, Implementasi dan Kontrol. Edisi 9. Penterjemah Hendra Teguh. Penerbit PT. Prenhallindo. Jakarta.

Kotler, Philip. 2005. Manajemen Pemasaran Edisi Bahasa Indonesia Jilid I. Jakarta: PT Prenhallindo.

Kotler, Philip. (2010). Manajemen Pemasaran. Jakarta: PT. Prenhalindo.

Muhammad. (2005). Manajemen Bank Syariah. Yogyakarta: AMPYKPN.

Parasuraman, A.; Zeithaml Valerie A. and Leonard L. Berry. 1994. Reassessment of Expectations as a Comparisson Standard in Measuring Service Quality: Implications for Futhers Research. Journal of Marketing Vol. 58 (January): 111124.

Bhakti, Yoga Budi dan Rahmawati, Eva Yuni. 2017. Indeks Kepuasan Mahasiswa Terhadap Pelayanan Program Studi Pendidikan Matematika. Jurnal Formatif 7(3): 272-285.

Solimun, 2006. Metode Statistika. Malang: FMIPA Universitas Brawijaya.

Stanton, William J.; Michael J. Etsel and Bruce J. Walker. 1991. Fundamental of Marketing 9th ed. McGraw-Hill, Inc. New York.

Supranto, J. 2002. Metode Riset: Aplikasinya Dalam Pemasaran. Edisi Revisi. Penerbit PT. Rineka Cipta. Jakarta.

Tjiptono, Fandy. 1997. Manajemen Jasa. Penerbit Andi Offset. Yogyakarta.

Tjiptono, F. (2012). Manajemen Jasa, dan Service Management. Yogyakarta: Andi.

Tjiptono, F. \& G. Candra, (2012). Service, Quality dan Satisfaction. Yogyakarta: Andi.

Undang-Undang Nomor 20 Tahun 2003 tentang Sistem Pendidikan Nasional.

Wijatno, S. 2009. Pengelolaan Perguruan Tinggi Secara Efisien, Efektif, dan Ekonomis (Untuk Meningkatkan Mutu Penyelenggaraan Pendidikan dan Mutu Lulusan). Jakarta: Salemba Empat.

Zeithaml, Valerie A. and Mary Jo Bitner, 1996. Services Marketing. New York: The McGraw-Hill Companies. Inc. 